\title{
Predictors of visit frequency for patients using ongoing chiropractic care for chronic low back and chronic neck pain; analysis of observational data
}

\author{
Patricia M. Herman ${ }^{*}$ (D), Sarah E. Edgington ${ }^{1}$, Eric L. Hurwitz ${ }^{2}$ and lan D. Coulter ${ }^{1}$
}

\begin{abstract}
Background: Chronic spinal pain is prevalent, expensive and long-lasting. Several provider-based nonpharmacologic therapies have now been recommended for chronic low-back pain (CLBP) and chronic neck pain (CNP). However, healthcare and coverage policies provide little guidance or evidence regarding the long-term use of this care. To provide one glimpse into the long-term use of nonpharmacologic provider-based care, this study examines the predictors of visit frequency in a large sample of patients with CLBP and CNP using ongoing chiropractic care.
\end{abstract}

Methods: Observational data were collected from a large national sample of chiropractic patients in the US with non-specific CLBP and CNP. Visit frequency was defined as average number of chiropractic visits per month over the 3-month study period. Potential baseline predictor variables were entered into two sets of multi-level models according to a defined causal theory - in this case, Anderson's Behavioral Model of Health Services Use.

Results: Our sample included 852 patients with CLBP and 705 with CNP. Visit frequency varied significantly by chiropractor/clinic, so our models controlled for this clustering. Patients with either condition used an average of 2.3 visits per month. In the final models visit frequency increased ( 0.44 visits per month, $p=.008$ ) for those with CLBP and some coverage for chiropractic, but coverage had little effect on visits for patients with CNP. Patients with worse function or just starting care also had more visits and those near to ending care had fewer visits. However, visit frequency was also determined by the chiropractor/clinic where treatment was received. Chiropractors who reported seeing more patients per day also had patients with higher visit frequency, and the patients of chiropractors with 20 to 30 years of experience had fewer visits per month. In addition, after controlling for both patient and chiropractor characteristics, the state in which care was received made a difference, likely through state-level policies and regulations.

Conclusions: Chiropractic patients with CLBP and CNP use a range of visit frequencies for their ongoing care. The predictors of these frequencies could be useful for understanding and developing policies for ongoing providerbased care.

Keywords: Chronic low back pain, Chronic neck pain, Chiropractic care, Visit frequency, Behavioral model of health services use

\footnotetext{
* Correspondence: pherman@rand.org

1 RAND Corporation, Santa Monica, CA, USA

Full list of author information is available at the end of the article
}

(c) The Author(s). 2020 Open Access This article is licensed under a Creative Commons Attribution 4.0 International License, which permits use, sharing, adaptation, distribution and reproduction in any medium or format, as long as you give appropriate credit to the original author(s) and the source, provide a link to the Creative Commons licence, and indicate if changes were made. The images or other third party material in this article are included in the article's Creative Commons licence, unless indicated otherwise in a credit line to the material. If material is not included in the article's Creative Commons licence and your intended use is not permitted by statutory regulation or exceeds the permitted use, you will need to obtain permission directly from the copyright holder. To view a copy of this licence, visit http://creativecommons.org/licenses/by/4.0/. The Creative Commons Public Domain Dedication waiver (http://creativecommons.org/publicdomain/zero/1.0/) applies to the data made available in this article, unless otherwise stated in a credit line to the data. 


\section{Background}

Chronic low back pain (CLBP) and chronic neck pain (CNP) are the most common types of chronic pain, [1, 2] and their estimated combined adult prevalence is between 10 and 20\% [1,3-11]. This pain is associated with substantial co-morbidity, [12] and is expensive to the healthcare system [13] and to employers [14]. Chronic spinal pain is also long-lasting, with average pain durations from years to decades [15-19].

Many patients with CLBP and/or CNP use medications to manage their pain, including opioids $[12,20]$. However, due to the dangers of opioid abuse, recent efforts have focused on finding effective nonpharmacologic therapies [21]. Guidelines now recommend a number of nonpharmacologic therapies for CLBP and CNP [22-24]. Several of these therapies (e.g., acupuncture, cognitive-behavioral therapy, multidisciplinary rehabilitation, spinal manipulation) require ongoing visits to providers.

Unfortunately, the ongoing long-term provision of provider-based care for chronic spinal pain, including appropriate visit frequencies, is not well-addressed in health and payer policies [25-27]. To some extent this is because many of these policies are based on a curative model [28, 29]-i.e., X number of treatments and you should be cured. These policies can require documentation of continued clinically meaningful improvement with the implication that treatment ends when a patients' symptoms plateau at some maximum therapeutic benefit [30-35]. However, although many policies recognize that care beyond this plateau-i.e., chronic pain management [32] or ongoing or support care [35] - might be needed under certain conditions-e.g., if symptoms deteriorate with treatment withdrawal [30-32, 36]-little guidance and no evidence is offered for this care. This lack of information and support of ongoing pain management has been cited as one barrier to the use of recommended provider-based nonpharmacologic therapies for chronic spinal pain [37].

Information on how patients with CLBP and CNP utilize ongoing provider-based nonpharmacologic care may be useful to the development of better policies in support of this care. It is estimated that $30 \%$ of patients with spinal pain have visited a chiropractor, one type of recommended provider-based nonpharmacologic care [38]. In particular, it would be useful to examine the treatment frequency patients used, and the determinants of those frequencies. These determinants include patient characteristics but may also include characteristics of the treating chiropractors.

This study took advantage of data gathered from a large national sample of patients with CLBP and CNP who were using chiropractic care [15]. Other analyses of these data have shown that this sample matches the age, gender, racial, ethnic, income and education levels seen in other national samples of chiropractic patients [15, 38-42]. It has also been shown that these patients have been in pain for an average of 14 years and have been using chiropractic care for an average of 11 years [15]. The majority have a goal of pain management (not cure) [43]. A study of their stated willingness-to-pay for pain reduction indicated that what they value is the maintenance of their current, generally mild pain levels, [44] and on average their symptoms over the 3-month study period are mild (average pain intensity of 3 and 4 on a $0-10$ scale with minimal-tomoderate back dysfunction [45] and mild neck dysfunction $[15,46])$ and may improve slightly [47]. This last may indicate that they have plateaued at maximum therapeutic benefit. However, on average these patients reported that their pain would double if they did not see their chiropractor, [15] which could be an indication of their experience with treatment withdrawals. In this study we examined the range of visit frequencies (visits/month) these patients used to determine the effect on this behavior of baseline insurance coverage, patient characteristics and the characteristics of the treating chiropractor.

\section{Methods}

This study uses observational data collected over 3 months from a national sample of US chiropractors and their patients with CLBP and CNP. These data were gathered between June 2016 and February 2017 as part of a larger project which has been described elsewhere $[48,49]$. Data collection and general characteristics of the sample were also documented in detail elsewhere [15, 50-52]. In brief, this study used a 4-level multistage systematic stratified sampling plan (regions/states, metropolitan areas, chiropractic providers/clinics, and patients) to recruit 20 chiropractic clinics and their patients from each of 6 US regions: Dallas, Texas; Minneapolis, Minnesota; Portland, Oregon; San Diego, California; Tampa, Florida; and Seneca Falls/Upstate, New York. Chiropractors were selected to reflect US national proportions of provider gender, years of experience and patient load as shown in the 2015 Practice Analysis Report from the National Board of Chiropractic Examiners [53].

To minimize the burden on clinic operations each clinic front office staff were asked to offer each patient who visited the clinic over the 4-week recruitment period an iPad upon which to fill out a brief prescreening questionnaire. After that point all patient screening, consent and data collection occurred online and did not involve the clinic. Those who filled out the prescreening questionnaire, met those criteria ( $\geq 21$ years of age; English proficient; no present personal injury/workers compensation litigation; have low back or neck pain) and gave their email address were sent a longer online screening questionnaire to determine their eligibility for the study-i.e., patients with chronic low-back pain and/ or chronic neck pain (i.e., pain of $\geq 3$-month duration 
before starting chiropractic care or patient-reported chronicity). Eligible patients gave consent, answered several additional questions and then were sent an online baseline survey followed by five shorter biweekly followups to collect data on ongoing care and symptoms, and a longer endline survey at 3 months. At each step, in addition to the survey link respondents were sent up to 3 email reminders and if they missed a survey they were allowed to rejoin the series at any point past baseline. Patients received online gift cards for their response to each questionnaire and those who completed all nine questionnaires received a total of $\$ 200$. This study used visit data from all surveys. However, all other data came from the baseline and screening questionnaires. The chiropractor at each clinic also filled out a questionnaire about their own and their clinic's characteristics. Because the evidence for nonpharmacologic therapies has focused on non-specific CLBP and CNP, in this study we excluded patients from our sample if they reported that a health practitioner told them that their CLBP and/or CNP was caused by one of a list of medical conditions including cancer, rheumatoid arthritis, spinal stenosis, primary fibromyalgia or fracture.

We specified and estimated 2 sets of multi-level models. The first set examined the predictors of chiropractic visit frequency for those with only CLBP or with both CLBP and CNP but who said that their CLBP was worse (hereafter referred to as those with CLBP). The second set examined the predictors of visit frequency for those with only CNP or with both but said that their CNP was worse (hereafter known as those with CNP).

\section{Measures}

Visit frequency was based on patient self-reported recall of chiropractic use over the past two weeks gathered every two weeks for 3 months. Visit frequency was defined as the average number of chiropractic visits per 30-day month. If patients missed data collection points they were asked for their number of visits since their last data collection and numbers were adjusted accordingly. Patients who dropped out or ended care before the end of the first month were excluded from the analysis. The variables we hypothesized to predict visit frequency were all measured at baseline and are listed below in descending order of their hypothesized importance following Anderson's Behavioral Model of Health Services Use [54-56].

We measured the enabling factors of patients' baseline insurance coverage and resulting out-of-pocket costs for chiropractic care in three ways and chose the one that best explained visit frequency. The first is a dichotomous variable for having some coverage or not. The second provides more detail on any limitations (e.g., visit or dollar caps) on coverage. And since insurance coverage has a direct effect on the amount the patient pays out-of- pocket per visit, we also considered including these costs instead.

Patients' need factors included the characteristics of their baseline pain and function. We included their pain 0-10 numerical rating scale or NRS, [57] and the 10item Neck Disability Index (NDI) [58] score for those with CNP and the 10-item Oswestry Disability Index (ODI) [45] score for those with CLBP. These are all recommended, valid and reliable (pain NRS [59-63]; NDI [46, 64-66]; ODI [67-69]) measures. We also included what patients reported at baseline as to their duration of pain and whether a respondent had both CLBP and CNP. Research has shown that those with both types of chronic pain have worse outcomes, [70] and duration of pain may be a justification for ongoing care [32].

Certain lifestyle or point in care characteristics could also be considered need factors affecting visit frequency. Higher physical demands (i.e., time spent in heavy labor or physically demanding tasks) have been hypothesized as a justification for ongoing care [32]. Also, being a new ( $<30$-day) patient or a patient who is getting ready to end care may affect visit frequency.

Patients' goals for their care may reflect perceived need factors and affect visit frequency. These goals were elicited in the baseline survey using an item asking for those with CLBP: Which of the following best describes what you hope to get from your chiropractor regarding your low back pain? The four response options were: Prevent low back pain from coming back or prevent reinjury; Prevent low back pain from getting worse; Ease low back pain or make low back pain go away temporarily; and Make low back pain go away permanently (cure). Those with CNP received a similar item and set of responses but asking about neck pain.

Pain beliefs may also be considered perceived need factors and were captured using several measures including patient report of whether they believed their pain was chronic, and what would happen to their pain on a scale of $0-10$ if they did not see their chiropractor. This last question was added after pilot studies indicated that this seemed to motivate patients more than their current pain levels, and later analyses confirmed this focus [44]. Patients also reported their level of agreement $(1=$ agree to strongly agree) with a series of statements about chronic pain, including that chronic pain will never go away, it is important for me to understand what causes my pain, and it is unsafe for someone with my condition to be physically active (a rough measure of fear avoidance [32, 71, 72]).

Certain psychological variables may also be perceived need factors and associated with visit frequency. Patients' self-efficacy for their pain management was measured at baseline using that 5-item subscale of the Chronic Pain Self-Efficacy Scale [73] and used patient 
response averages across items from $1=$ very uncertain to $10=$ very certain as to their ability to accomplish each statement. Expectations were measured using two items from the Credibility/Expectancy Questionnaire: how successful your chiropractor will be in reducing your pain $(1=$ very/extremely successful), and how much improvement in pain do you expect over the next 3 months ( $1=\mathrm{a}$ lot/quite a bit of improvement) [74]. Expectancy has been shown in other studies to positively effect outcomes [75] and was suggested as one justification for ongoing care [32]. Worry and anxiety are associated with worse outcomes, $[72,76]$ and may be related to treatment frequency. We included an item regarding how often a statement that I worry all the time about whether pain will end is true $(1=$ to a moderate or great degree/all the time). Those who are depressed have worse outcomes, $[71,76]$ and may be justified to receive ongoing care [32]. We used the 4-item depression scale from the PROMIS-29 v2.0 and indicated those with mild depression or above (scores > 52.5) [77, 78]. Finally, there is some evidence that pain catastrophizing is associated with outcomes, [75, 79-81] and may affect patients' visit frequency. We measured catastrophizing using the sum of $0-4$ scores from 3 items asking how often these statements are true: I worry all the time about whether the pain will end, I think the pain is never going to get any better, there is nothing I can do to reduce the intensity of the pain.

Finally, we included several predisposing factors (age, gender and education) to examine their impacts on visit frequency. Several studies have found that those who are older respond less favorably to treatment, [17, 82, 83] and age may be a justification for ongoing care [32]. CLBP outcomes have also been found to be associated with level of (Bachelor's degree or higher) education [84, 85].

Variables for clinic (chiropractor) and region (state and metropolitan area) were used to determine whether visit frequency was clustered by clinic or region. If clustering by clinic was found, we added chiropractor/clinic characteristics to the model to see if they explain how visit frequency varied by clinic, including average number of patients treated per day, percentage of patients seen for preventive/ maintenance care, years in practice, clinic location as urban $(\geq 50,000$ population $[86,87])$, and whether and how many of five physical modalities (electrical therapy, heat therapy, hydrotherapy, ice therapy, and ultrasound) were used. We also examined the effect of the college where the chiropractor trained. Finally, if clustering by region was found we included state in which the clinic is located to capture any effects of differences in licensure or insurance coverage by state.

\section{Analysis}

We used hierarchical linear modeling (HLM, aka multilevel modeling or mixed models [88-90]) to account for the potential clustering of patients within clinics and regions/states. HLM offered several statistical benefits, including that it corrects for error structure violations (e.g., non-independent errors [88, 91]).

We first ran unconditional (no predictor variables) HLM models to determine whether visit frequency was clustered by region and/or by chiropractor/clinic. We used the Bayesian Information Criterion (BIC) fit statistic (smallest value) to choose the best unconditional model in terms of clustering variable [92]. The BIC was also used to choose the best form of the coverage variable to include in the models. If the difference between BIC statistics for two models is greater than 10, that can be considered "very strong evidence" that the model with the lower BIC is a better fit to the data [93].

Blocks of explanatory variables were then entered into each model sequentially according to a defined causal theory [94]. The work by Andersen and others provided the basis for the models [54-56]. Each block contained a set of related available variables believed to define the causal mechanism in question: enabling, need, perceived need and predisposing factors. The blocks were ordered from those hypothesized to be most proximal to those most distal in explaining an individual's use of chiropractic care. Because visit frequency could also be affected by chiropractor/clinic characteristics (clustered by chiropractor/clinic) and/or by region even after patientlevel characteristics are included, those variables were added last. Sequential entry of these blocks allowed the incremental explanatory power of each block to be measured and tested in a logical order using likelihood-ratio tests. The estimated coefficients reported were derived from the final models (i.e., the models containing all blocks of variables), but only shown for the blocks of variables found to add significant explanatory power $(p<.05)$ for at least one condition. The $p$-values for each reported coefficient are provided as an indication of the variables providing the most explanatory power in that block.

Averages and frequencies for the variables considered as potential predictors of patients' visit frequency were compared between the CLBP and CNP samples using ttests and $X^{2}$ tests, respectively. All analyses were performed in Stata 16.0. This study was approved by the RAND Human Subjects Protection Committee.

\section{Results}

Of the 2024 chiropractic patients with CLBP and CNP who completed the baseline survey, [15] 1708 met our criterion for non-specific CLBP or CNP (Fig. 1). Of these 1557 (91.2\%) patients of 124 chiropractors had sufficient 


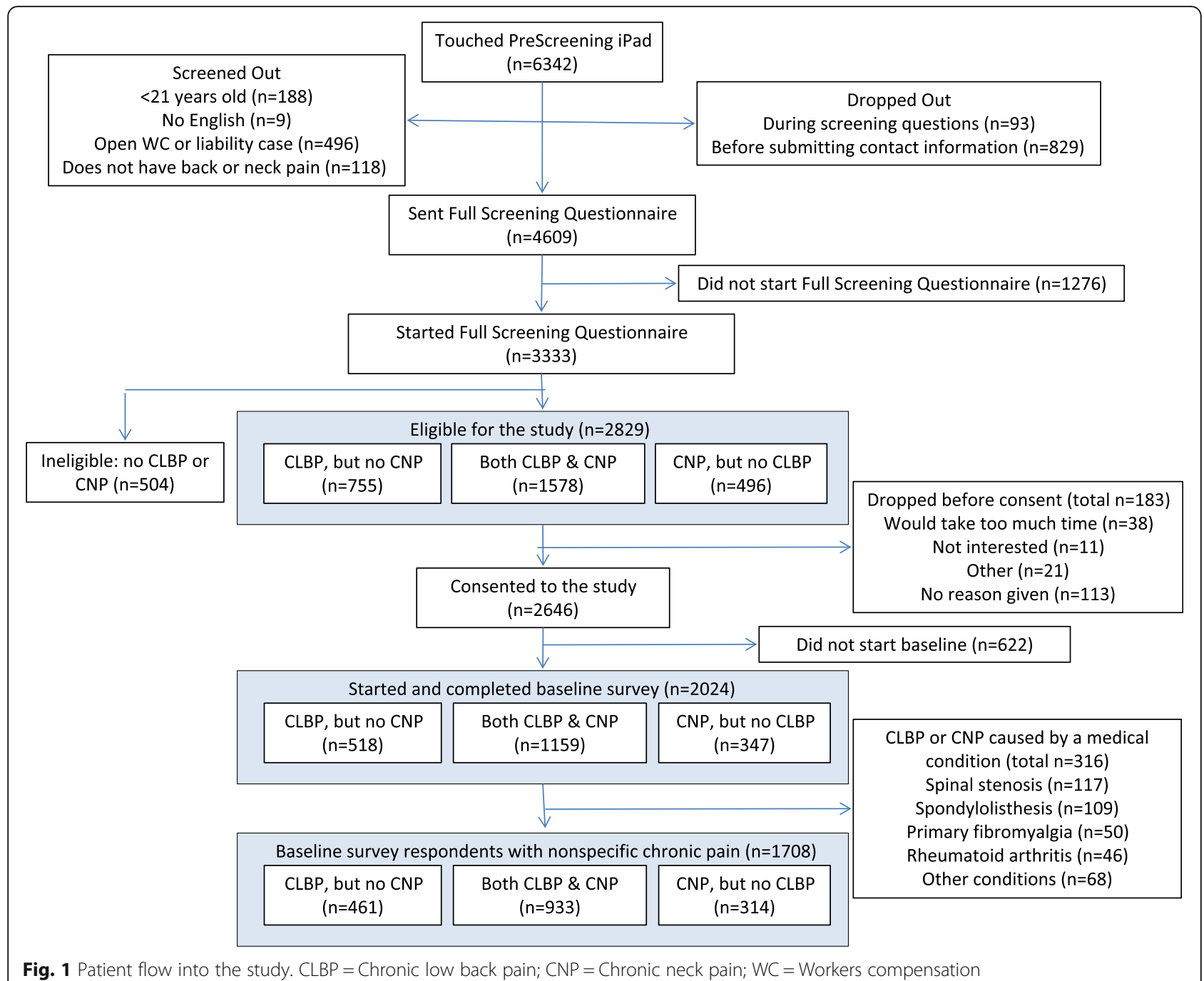

Fig. 1 Patient flow into the study. CLBP = Chronic low back pain; CNP = Chronic neck pain; $W C=$ Workers compensation

data (including at least one month of data on their chiropractic visits after baseline) to be included in our analyses-852 with non-specific CLBP and 705 with non-specific CNP.

Our unconditional HLM models indicated that the variance in visit frequency across patients was significantly clustered by chiropractor/clinic $(p<.001$ for both the CLBP and CNP models)-i.e., visit frequency was at least partially explained by the chiropractor seen. Clustering by region was not significant and the lowest BIC was found for an unconditional model that only clustered by clinic (Appendix Table A.1). The BICs for the models clustered by clinic were 50 (CLBP) and 44 (CNP) points lower than models with no clustering.

Table 1 shows the averages and frequencies of the variables included in each of the three blocks we considered to represent coverage status for chiropractic care: some coverage/no coverage (columns), more detail on coverage characteristics, and out-of-pocket costs per visit. As can be seen those with some coverage paid significantly less out-of-pocket for care for both conditions $(p<.001)$.

Table 2 shows the means and frequencies of each of the predictor variables by block for each sample. The average visit frequency per month was 2.3 for both conditions, a bit more often than every other week. Median visits per month were 1.7 for both conditions and visit frequency ranged from 0 to 14.7 per month for CLBP and 0 to 13.6 for CNP [data not shown]. Almost half have had their pain for 10 or more years and few (7\% of those with CLBP and $4 \%$ of those with CNP) ended their care (both no visits since last data collection point and report that care has ended) during the last 2 months of the 3-month study period. As can be seen these two samples were remarkably similar. The main exceptions were that CNP patients reported significantly higher pain intensity, worse function, were more likely to have both CNP and CLBP, had somewhat different goals for treatment, were younger, and were more likely to be 
Table 1 Alternate versions of enabling factors (coverage for chiropractic and costs per visit) to be tested

\begin{tabular}{|c|c|c|c|c|}
\hline & \multicolumn{2}{|l|}{ Chronic Low Back Pain ${ }^{1}$} & \multicolumn{2}{|l|}{ Chronic Neck Pain ${ }^{1}$} \\
\hline & No coverage $(n=218)$ & Some coverage $(n=590)$ & No coverage $(n=202)$ & Some coverage $(n=475)$ \\
\hline Mean (SD) \# chiropractic visits/month & $2.0(1.6)$ & $2.4(2.4)$ & $2.3(2.1)$ & $2.2(2.0)$ \\
\hline \multicolumn{5}{|l|}{ Enabling factors } \\
\hline Insurance with caps on visits or costs & - & $291(49.3 \%)$ & - & $244(51.4 \%)$ \\
\hline Insurance with no caps & - & $85(14.4 \%)$ & - & $68(14.3 \%)$ \\
\hline Insurance with unknown caps & - & $214(36.3 \%)$ & - & $163(34.3 \%)$ \\
\hline \multicolumn{5}{|l|}{ Out-of-pocket costs per visit* } \\
\hline Unknown / \$0 & $0(0.0 \%)$ & $67(11.4 \%)$ & $0(0.0 \%)$ & $69(14.5 \%)$ \\
\hline$\$ 1$ to $\$ 20$ & $0(0.0 \%)$ & $227(38.5 \%)$ & $0(0.0 \%)$ & $148(31.2 \%)$ \\
\hline$\$ 21$ to $\$ 40$ & $14(6.4 \%)$ & $195(33.1 \%)$ & $19(9.4 \%)$ & $175(36.8 \%)$ \\
\hline$\$ 41$ to $\$ 60$ & $101(46.3 \%)$ & $65(11.0 \%)$ & $89(44.1 \%)$ & $51(10.7 \%)$ \\
\hline$\$ 61$ to $\$ 80$ & $71(32.6 \%)$ & $18(3.1 \%)$ & $72(35.6 \%)$ & $18(3.8 \%)$ \\
\hline$\$ 81+$ & $32(14.7 \%)$ & $18(3.1 \%)$ & $22(10.9 \%)$ & $14(2.9 \%)$ \\
\hline
\end{tabular}

'Data on insurance status were not available for a small percentage of patients in each sample: 44 (5.2\%) for chronic low back pain and 28 (4.0\%) for chronic neck pain

"Out-of-pocket costs differ significantly between those with and without some chiropractic coverage for both those with chronic low back pain and chronic neck pain, $\mathrm{p}<.001$

female. Appendix Table A.2 gives the average visit frequency seen across each of these variables.

We first separately added each of the three options for coverage and out-of-pocket costs to the unconditional HLM models clustered by clinic (Appendix Table A.3). These runs indicated that the best version of the coverage variable block (lowest BICs by 10-12 points for both models) had 3 categories: some coverage, unknown coverage, and no coverage as the reference. We then sequentially added each of the other variable blocks to models with this coverage variable. Table 3 reports in italics the explanatory power (statistical significance) of each block when it was first entered. As can be seen the blocks of perceived need factors (treatment goals, pain beliefs, and other psychological variables) were not explanatory when added after enabling or need factors for either model. Estimated coefficients from the final models were reported in Table 3 for each variable in the blocks with significant explanatory power in at least one model. In general, the same coefficients remained statistically significant as additional blocks of explanatory variables were added. All estimated coefficients with their 95\% confidence intervals are shown in Appendix Table A.4.

Having some insurance coverage increases visit frequency by 0.44 visits per month for patients with CLBP but has little to no effect for CNP. Having worse function (higher ODI/NDI scores) and being a newer patient increased visit frequency for both CLBP and CNP. For those with CLBP having some heavy labor at work increased visit frequency and being female decreased visit frequency. On the other hand, those who ended care during the last 2 months of the 3-month study period already had significantly fewer visits before their decision to end.
Even after accounting for all available patient characteristics, the characteristics of the treating chiropractors provided significant explanatory power to patients' visit frequency. Visit frequency was significantly higher for patients of chiropractors who reported treating more patients per day and was significantly lower for patients of chiropractors who have been in practice for 20-30 years. Visit frequency was also significantly higher for patients with CNP when the chiropractor reported a higher proportion of patients being seen for preventive/maintenance care. The block for the chiropractor's college of graduation did not add significant explanatory power to either model. However, after controlling for all patient and chiropractor characteristics visit frequency was still significantly lower for patients in New York state. After the last block was added to each model, the variance in visit frequency by chiropractor/clinic was no longer significant meaning that the variables added successfully captured the influence of the chiropractor on patient visit frequency.

\section{Discussion}

In these samples of patients with CLBP and CNP who were using ongoing chiropractic care, average visit frequency was 2.3 chiropractic visits per month-i.e., just over one visit every two weeks. This visit frequency was found to vary significantly by the characteristics of the patients, the characteristics of the treating chiropractors, and the state in which care was given.

Patients with CLBP and some insurance coverage for chiropractic had on average less than one-half visit more per month than those without coverage. However, insurance coverage had little to no effect on visit frequency for patients with CNP. In other analyses about two- 
Table 2 Means and frequencies of each predictor variable in each sample in order of model entry

\begin{tabular}{|c|c|c|c|}
\hline All figures are $\mathrm{n}(\%)$ unless otherwise indicated & $\begin{array}{l}\text { Chronic Low Back Pain } \\
(n=852)\end{array}$ & $\begin{array}{l}\text { Chronic Neck Pain } \\
(n=705)\end{array}$ & $\begin{array}{l}\text { p-value for difference } \\
\text { between groups }\end{array}$ \\
\hline Mean (SD) \# chiropractic visits/month & $2.3(2.2)$ & $2.3(2.0)$ & .900 \\
\hline \multicolumn{4}{|l|}{ Enabling factors } \\
\hline Some insurance coverage for chiropractic & $590(69.2 \%)$ & $475(67.4 \%)$ & .520 \\
\hline Unknown insurance coverage & $44(5.2 \%)$ & $28(4.0 \%)$ & \\
\hline \multicolumn{4}{|l|}{ Need factors - pain characteristics } \\
\hline Rating of pain past 7 days $(0-10)$, mean (SD) & $3.7(2.1)$ & $4.0(2.1)$ & .004 \\
\hline Oswestry or Neck Disability Index score (0-100), mean (SD) & $20.5(12.5)$ & $22.6(12.5)$ & .001 \\
\hline Have both CLBP and CNP & $444(52.1 \%)$ & $428(60.7 \%)$ & .001 \\
\hline Years of pain & & & .278 \\
\hline Less than 1 year & $107(12.6 \%)$ & $80(11.3 \%)$ & \\
\hline 1 year to less than 2 years & $58(6.8 \%)$ & $38(5.4 \%)$ & \\
\hline 2 years to less than 5 years & $115(13.5 \%)$ & $112(15.9 \%)$ & \\
\hline 5 years to less than 10 years & $134(15.7 \%)$ & $133(18.9 \%)$ & \\
\hline $10+$ years & $418(49.1 \%)$ & $324(46.0 \%)$ & \\
\hline Unknown & $20(2.3 \%)$ & $18(2.6 \%)$ & \\
\hline \multicolumn{4}{|l|}{ Need factors - lifestyle and point in care } \\
\hline No heavy labor & $401(47.1 \%)$ & $375(53.2 \%)$ & .063 \\
\hline Non-workday heavy labor: $>0 \%$ but $<20 \%$ & $108(12.7 \%)$ & $68(9.6 \%)$ & \\
\hline Workday heavy labor: $>0 \%$ but $<20 \%$ & $163(19.1 \%)$ & $140(19.9 \%)$ & \\
\hline Non-workday heavy labor: $\geq 20 \%$ & $30(3.5 \%)$ & $15(2.1 \%)$ & \\
\hline Workday heavy labor: $\geq 20 \%$ & $87(10.2 \%)$ & $58(8.2 \%)$ & \\
\hline Heavy labor: missing & $63(7.4 \%)$ & $49(7.0 \%)$ & \\
\hline New patient ( $<30$ days) & $94(11.0 \%)$ & $73(10.4 \%)$ & .763 \\
\hline Unknown time with this chiropractor & $145(17.0 \%)$ & $113(16.0 \%)$ & \\
\hline Ended care during study period & $57(6.7 \%)$ & $29(4.1 \%)$ & 0.027 \\
\hline Perceived need factors - goals for treatment & & & .001 \\
\hline Goal: prevent pain getting worse & $120(14.1 \%)$ & $84(11.9 \%)$ & \\
\hline Goal: prevent pain coming back; prevent reinjury & $178(20.9 \%)$ & $107(15.2 \%)$ & \\
\hline Goal: ease or make pain go away temporarily & $268(31.5 \%)$ & $290(41.1 \%)$ & \\
\hline Goal: make pain go away permanently & $276(32.4 \%)$ & $218(30.9 \%)$ & \\
\hline Goal: other or missing & $10(1.2 \%)$ & $6(0.9 \%)$ & \\
\hline \multicolumn{4}{|l|}{ Perceived need factors - pain beliefs } \\
\hline Believe their pain is chronic & $572(67.1 \%)$ & $474(67.2 \%)$ & .967 \\
\hline What pain would be if didn't see chiropractor 0-10, mean (SD) & $6.8(2.3)$ & $6.9(2.2)$ & .179 \\
\hline Chronic pain will never go away: agree/strongly agree & $235(27.6 \%)$ & $198(28.1 \%)$ & $<.001$ \\
\hline Important to understand causes of pain: agree/strongly agree & $801(94.0 \%)$ & $669(94.9 \%)$ & .452 \\
\hline Unsafe to be physically active: agree/strongly agree & $53(6.2 \%)$ & $25(3.5 \%)$ & .016 \\
\hline \multicolumn{4}{|l|}{ Perceived need factors - other psychological influences } \\
\hline Pain management self-efficacy (0-10), mean (SD) & $7.5(1.8)$ & $7.7(1.7)$ & .061 \\
\hline Expect chiropractic very-extremely successful & $611(71.7 \%)$ & $542(76.9 \%)$ & .021 \\
\hline Expect a lot to quite a bit of improvement & $538(63.1 \%)$ & $447(63.4 \%)$ & .916 \\
\hline Worry about pain: mod to all the time & $152(17.8 \%)$ & $116(16.5 \%)$ & .471 \\
\hline Has depression according to PROMIS items & $215(25.2 \%)$ & $188(26.7 \%)$ & .521 \\
\hline
\end{tabular}


Table 2 Means and frequencies of each predictor variable in each sample in order of model entry (Continued)

\begin{tabular}{|c|c|c|c|}
\hline All figures are $\mathrm{n}(\%)$ unless otherwise indicated & $\begin{array}{l}\text { Chronic Low Back Pain } \\
(n=852)\end{array}$ & $\begin{array}{l}\text { Chronic Neck Pain } \\
(n=705)\end{array}$ & $\begin{array}{l}\mathrm{p} \text {-value for difference } \\
\text { between groups }\end{array}$ \\
\hline Catastrophizing (0-12 scale), mean (SD) & $2.3(2.3)$ & $2.2(2.3)$ & .389 \\
\hline \multicolumn{4}{|l|}{ Predisposing factors } \\
\hline Age in years & $48.5(14.9)$ & $45.8(13.2)$ & $<.001$ \\
\hline Female & $558(65.5 \%)$ & 579 (82.1\%) & $<.001$ \\
\hline Education: At least a 4-year degree & $462(54.2 \%)$ & $413(58.6 \%)$ & .085 \\
\hline \multicolumn{4}{|l|}{ Chiropractor practice characteristics } \\
\hline Average number of patients treated per day & $25.3(12.8)$ & $25.6(12.3)$ & .612 \\
\hline Percentage of patients on preventive/maintenance & $23.7(17.3)$ & $24.1(17.4)$ & .660 \\
\hline In practice 5 to 10 years & $100(11.7 \%)$ & $84(11.9 \%)$ & .598 \\
\hline In practice $>10$ to 20 years & $268(31.5 \%)$ & $222(31.5 \%)$ & \\
\hline In practice $>20$ to 30 years & $258(30.3 \%)$ & $231(32.8 \%)$ & \\
\hline In practice $>30$ years & $226(26.5 \%)$ & $168(23.8 \%)$ & \\
\hline Clinic location is urban ( $>50,000$ population) & $541(63.5 \%)$ & $477(67.7 \%)$ & .086 \\
\hline Average number of physical modalities used & $3.3(1.4)$ & $3.2(1.4)$ & .849 \\
\hline College from which chiropractor graduated & & & .344 \\
\hline Life College & $79(9.3 \%)$ & $63(8.9 \%)$ & \\
\hline National College of Chiropractic [fix order later] & $46(5.4 \%)$ & $42(6.0 \%)$ & \\
\hline Los Angeles College of Chiropractic & $28(3.3 \%)$ & $29(4.1 \%)$ & \\
\hline New York Chiropractic College & $90(10.6 \%)$ & $54(7.7 \%)$ & \\
\hline Northwestern Chiropractic College & $212(24.9 \%)$ & 199 (28.2\%) & \\
\hline Palmer Chiropractic College & $106(12.4 \%)$ & $94(13.3 \%)$ & \\
\hline Parker Chiropractic College & $73(8.6 \%)$ & $45(6.4 \%)$ & \\
\hline Texas Chiropractic College & $81(9.5 \%)$ & $58(8.2 \%)$ & \\
\hline University of Western States & $106(12.4 \%)$ & $97(13.8 \%)$ & \\
\hline Other & $31(3.6 \%)$ & $24(3.4 \%)$ & \\
\hline State/Region & & & .038 \\
\hline California & $130(15.3 \%)$ & 125 (17.7\%) & \\
\hline Florida & $71(8.3 \%)$ & $56(7.9 \%)$ & \\
\hline Minnesota & $208(24.4 \%)$ & $199(28.2 \%)$ & \\
\hline New York & 155 (18.2\%) & 99 (14.0\%) & \\
\hline Oregon & $117(13.7 \%)$ & 111 (15.7\%) & \\
\hline Texas & 171 (20.1\%) & 115 (16.3\%) & \\
\hline
\end{tabular}

thirds of this sample said that having insurance coverage was very or extremely important to their use of chiropractic care [15]. However, those with coverage still face a variety of barriers to care that could limit visit frequency. These include high out-of-pocket expenses and other (e.g., travel, missed work) costs for every visit, visit limits, and prior authorization requirements [26]. Also, because we gathered these data from June of one year into February of the next, generally over the last months of a plan benefit year, we may have captured use of chiropractic for some patients after their coverage for the year had ended due to caps or limits.
As would be expected, patients with either CLBP or CNP and worse function had significantly higher visit frequency. Either going from the mid-point of minimal to the mid-point of moderate disability on the ODI for patients with CLBP (an increase of 30 points [45]) or going from the mid-point of mild to the mid-point of moderate disability on the NDI for patients with CNP (an increase of 20 points [46]) increased visit frequency by an average of about two-thirds of a visit per month. Patients' pain levels were not explanatory after controlling for coverage and other pain characteristics. It is also not surprising that those who were new patients $(<30$ days 
Table 3 Hierarchical linear model results predicting chiropractic visit frequency for patients with chronic spinal pain

\begin{tabular}{|c|c|c|c|c|}
\hline & $\begin{array}{l}\text { Chronic Low Back } \\
\text { Pain }(n=852)\end{array}$ & $\begin{array}{l}\text { p-values for } \\
\text { coefficients in } \\
\text { block }\end{array}$ & $\begin{array}{l}\text { Chronic Neck } \\
\text { Pain }(n=705)\end{array}$ & $\begin{array}{l}\text { p-values for } \\
\text { coefficients in } \\
\text { block }\end{array}$ \\
\hline Enabling factors - $p$-values for block ${ }^{1}$ & 0.032 & & 0.986 & \\
\hline Some insurance coverage for chiropractic - Reference $=$ No coverage & 0.44 & .008 & 0.14 & .408 \\
\hline Unknown insurance coverage & 0.06 & .845 & -0.15 & 689 \\
\hline Need factors - pain characteristics - p-values for block' & $<.001$ & & $<.001$ & \\
\hline Rating of pain past 7 days $(0-10)$, mean (SD) & 0.06 & .238 & 0.00 & .972 \\
\hline Oswestry or Neck Disability Index score (0-100), mean (SD) & 0.02 & .024 & 0.03 & $<.001$ \\
\hline Have both CLBP and CNP & 0.09 & .508 & 0.15 & .309 \\
\hline \multicolumn{5}{|l|}{ Years of pain - Reference $=<1$ year } \\
\hline 1 year to less than 2 years & 0.38 & .231 & 0.36 & .307 \\
\hline 2 years to less than 5 years & -0.26 & .338 & -0.07 & .787 \\
\hline 5 years to less than 10 years & -0.29 & .259 & -0.11 & .674 \\
\hline $10+$ years & -0.39 & .088 & -0.03 & .894 \\
\hline Unknown & -0.10 & .839 & -0.01 & .986 \\
\hline Need factors - lifestyle and point in care - $p$-values for block ${ }^{1}$ & $<.001$ & & $<.001$ & \\
\hline \multicolumn{5}{|l|}{ Heavy labor - Reference $=$ No heavy labor } \\
\hline Non-workday heavy labor: $>0 \%$ but $<20 \%$ & 0.41 & .055 & -0.28 & .244 \\
\hline Workday heavy labor: $>0 \%$ but $<20 \%$ & 0.47 & .010 & -0.06 & .732 \\
\hline Non-workday heavy labor: $\geq 20 \%$ & 0.23 & .533 & -0.02 & .971 \\
\hline Workday heavy labor: $\geq 20 \%$ & 0.22 & .350 & 0.19 & .458 \\
\hline Heavy labor: missing & 0.43 & .104 & 0.30 & .282 \\
\hline New patient (<30 days) & 0.63 & .006 & 0.69 & .005 \\
\hline Unknown time with this chiropractor & 0.32 & .082 & 0.45 & .019 \\
\hline Ended care during study period & -1.21 & $<.001$ & -1.57 & $<.001$ \\
\hline Perceived need factors - goals for treatment - $p$-values for block' & 0.636 & & 0.237 & \\
\hline Perceived need factors - pain beliefs - p-values for block ${ }^{1}$ & 0.063 & & 0.766 & \\
\hline Perceived need factors - other psychological factors - $p$-values for block ${ }^{1}$ & 0.295 & & 0.100 & \\
\hline Predisposing factors - $p$-values for block ${ }^{1}$ & 0.048 & & 0.171 & \\
\hline Age in years & 0.01 & .104 & 0.01 & .111 \\
\hline Female & -0.37 & .013 & -0.12 & .525 \\
\hline Education: At least a 4-year degree & 0.04 & .805 & -0.15 & .307 \\
\hline Chiropractor practice characteristics - $p$-values for block ${ }^{1}$ & $<.001$ & & $<.001$ & \\
\hline Average number of patients treated per day & 0.03 & $<.001$ & 0.04 & $<.001$ \\
\hline Percentage of patients on preventive/maintenance & 0.01 & .259 & 0.01 & .020 \\
\hline \multicolumn{5}{|l|}{ Years in practice - Reference $=5$ to 10 years } \\
\hline In practice $>10$ to 20 years & -0.50 & .072 & -0.16 & .567 \\
\hline In practice $>20$ to 30 years & -0.72 & .014 & -1.01 & .001 \\
\hline In practice $>30$ years & 0.24 & .487 & -0.13 & .704 \\
\hline Clinic location is urban ( $>50,000$ population) & -0.20 & .318 & -0.18 & .387 \\
\hline Average number of physical modalities used & -0.12 & .067 & -0.04 & .624 \\
\hline College from which chiropractor graduated - p-value for block ${ }^{1}$ & 0.130 & & 0.060 & \\
\hline State/Region - p-value for block ${ }^{1}$ & 0.014 & & 0.072 & \\
\hline \multicolumn{5}{|l|}{ State/Region - Reference $=$ California } \\
\hline Florida & -0.67 & .096 & -0.66 & .109 \\
\hline
\end{tabular}


Table 3 Hierarchical linear model results predicting chiropractic visit frequency for patients with chronic spinal pain (Continued)

\begin{tabular}{lllll}
\hline & $\begin{array}{l}\text { Chronic Low Back } \\
\text { Pain }(n=852)\end{array}$ & $\begin{array}{l}\text { p-values for } \\
\text { coefficients in } \\
\text { block }\end{array}$ & $\begin{array}{l}\text { Chronic Neck } \\
\text { Pain }(n=705)\end{array}$ & $\begin{array}{l}p \text {-values for } \\
\text { coefficients in } \\
\text { block }\end{array}$ \\
\hline Minnesota & -0.57 & .625 & -1.31 & .205 \\
New York & -1.49 & .001 & -1.20 & .010 \\
Oregon & 0.48 & .558 & 0.20 & .802 \\
Texas & -0.30 & .574 & -0.05 & .927 \\
\hline
\end{tabular}

${ }^{1} \mathrm{P}$-value for the likelihood-ratio test of the incremental explanatory power of each block of variables added to a model containing all previous blocks

with this chiropractor) had about two-thirds of a visit more per month, and those who were about to end care had significantly lower visit frequency-roughly monthly on average. Also, for patients with CLBP having some heavy labor increased visit frequency by less than half a visit per month and female patients had lower visit frequencies by just over a third of a visit per month. It is unclear why women with CLBP have fewer chiropractic visits per month than men.

Including all available patient characteristics explained some of the variation of visit frequency seen by chiropractor-i.e., some chiropractors tend to see more of certain types of patients. Nevertheless, including all available patient characteristics did not fully explain the variation in visit frequency seen by treating chiropractor. The characteristics of the chiropractor/clinic also had an influence on visit frequency. Patients of chiropractors who report treating more patients per day, and for CNP who report a higher proportion of patients receiving preventive/maintenance care, have significantly higher visit frequencies, and patients of chiropractors who have been in practice for 20-30 years have significantly lower visit frequencies. The patients of a chiropractor who treated double the average number of patients per day (50 rather than 25) had on average three-quarters to one more visit per month, and patients of chiropractors who have been in practice 20 to 30 years have roughly one less visit per month than those in practice for 5 to 10 years.

There has been concern amongst payers and providers that patients' use of ongoing care was not based on medical necessity or need, but on clinician dependence or coercion, including through lowered patient self-efficacy or heightened patient fear [32, 95-97]. We did find that a patients' visit frequency was to some extent determined by the chiropractor from which they received treatment. However, patient self-efficacy or worry did not seem to make a difference in visit frequency. In fact, the pain management self-efficacy scores in this sample were fairly high, and in line with patients' general belief that they have control over their pain [43]. Chiropractors who treat more patients per day also seem to have their patients return more often. This could simply be a strategy to generate more revenue, or there could be a valid relationship between shorter visits and the need for more visits. We also found that the patients of chiropractors who had been in practice 20 to 30 years had fewer visits than those of chiropractors who had practiced for 5 to 10 years. This effect could either be associated with an established practice's lower need to generate revenue, and/or that treatment from a more experienced practitioner reduced patients' need to return as often. The effects of a chiropractor's treatment approach and experience on visit frequency could be worthy targets for subsequent research. In any case, average patient visit frequency did not vary greatly across the chiropractors in our sample. Only 2 out of our sample of 124 chiropractors had average patient visit frequencies that were more than 2 standard deviations above the overall average of 2.3 visits per month-i.e., more than 6 visits per month [data not shown].

Finally, even after controlling for patient and chiropractor characteristics there seems to be some effect on visit frequency of being treated in New York State. Visit frequencies for patients with CLBP or CNP being treated in New York were more than one visit per month lower than patients being treated in California. This may be because of stricter coverage rules for chiropractic care in New York State.

Other studies have reported on visit frequency for chiropractic care. One study compared practice patterns over a year for patients with CLBP in chiropractic $(n=51)$ and primary medical care $(n=14)$ clinics [98]. They found an average number of visits per year of 6.7 for chiropractic care (median $=4$; range $=1-56$ ); just over an average of half a visit per month. The same numbers for medical care were 1.9 visits per year (median $=1$; range $=1-17$ ). Another study examined the use of chiropractic services from 1985 through 1991 in the US and Canada [40]. Across US sites the average duration of an episode of care for low back pain was 61.7 days and involved an average of 15.6 visits, so an average of 7.8 visits per month during an episode of care. It is possible that our estimate of an average of 2.3 visits per month is between these two previous estimates because we only followed our patients for 3 months (more could have ended or reduced their visit frequency over a year) and we didn't require patients be in an episode of care (no more than 30 days elapsed between visits) for the entire 3-month period. 


\section{Limitations}

This study benefits from extensive data collected from a large sample of patients using chiropractic for chronic non-specific spinal pain and from their chiropractors. Nevertheless, our study has limitations; the main one being that the sample used in this study is not a representative sample of all patients with CLBP and CNP. It is, however, a reasonably representative sample of chiropractic patients with CLBP and CNP [15] in terms of age, [38-42] having at least partial insurance coverage for chiropractic, [39, 41, 42] and high prevalence of women, [39-42] non-Hispanic whites, [39, 41, 42] those with higher income [42] and more education [39, 42]. The sample is also representative in terms of pain and function. Since everyone in our sample was receiving ongoing chiropractic care, we would expect that their pain and function levels would lie somewhere between the baseline and end-of-study scores seen in trials. For example, compare the baseline and end pain NRS (0-10) and ODI scores seen in a trial of manipulation for CLBP (baseline: pain $=6.0$, ODI $=29.5$; end-of-study: pain $=3.0$, ODI = 13.7) [19] to our sample's scores of 3.7 and 20.5. Also, compare the baseline and end pain and NDI scores seen in a trial of manipulation for CNP (baseline: pain = 5.6, $\quad$ ODI $=27.9$; $\quad$ end-of-study: pain $=3.5, \quad \mathrm{NDI}=19.5$ ) [18] to our sample's scores of 4.0 and 22.6. Although similar gender, racial/ethnic, income, and education profiles have also been found for those who used other types of nonpharmacologic therapy for back and neck problems, [38] our study's results should not be generalized to patients who are not now using these therapies. Nevertheless, this sample provides a real-world snapshot of how these patients were using chiropractic care over time.

Given the concern that patients utilize ongoing chiropractic care due to reasons such as clinician dependence or coercion for provider financial gain, another limitation of our study is that it would have been helpful to have a measure of whether patients' responses were based on what they were told by their chiropractor versus their lived experience. Their having lived with their pain condition for an average of 14 years and the consistency of their responses across the sample [15] give weight to responses based on lived experience. However, the variation of visit frequency by chiropractor also indicates their influence. Our analyses are also subject to the usual limitations of self-reported data. For example, we used patient report rather than administrative claims data to determine visit frequency. Whereas, claims data can be more accurate than patient recall, claims data would have only been available for those with insurance coverage and would not include the patient and chiropractor characteristics used in this study. However, despite these limitations, our models were able to account for all the variance in patient visit frequency attributable to the chiropractor/clinic. Note that this study did not examine the outcomes experienced by these patients, which would be important for the development of effective policies. Outcomes for this sample are addressed in the next paper in this series.

\section{Conclusions}

According to NIH Medline Plus, a publication of the National Institutes of Health, "chronic pain usually cannot be cured, but it can be managed." [99] Several providerbased nonpharmacologic therapies have been recommended for chronic spinal pain, and these therapies may be used on an long-term ongoing basis by patients for pain management. Despite this need, ongoing providerbased care is not well-addressed in the evidence or supported in health and payer policies, [25-27] and this adds another barrier to the use of these recommended nonpharmacologic therapies [37]. This study examined data from a large sample of patients with CLBP and/or CNP to see how these real-world patients used chiropractic care over time to manage their pain. Our sample patients' high pain management self-efficacy and longterm experience living with their conditions make them good source for information on how ongoing providerbased care for pain management might work. Chiropractic patients with CLBP and CNP manage their pain using a range of visit frequencies and the predictors of these frequencies could be useful for developing policies for ongoing provider-based care.

\section{Supplementary information}

Supplementary information accompanies this paper at https://doi.org/10. 1186/s12891-020-03330-1.

Additional file 1: Appendix Table A.1. Results of the unconditional models; Appendix Table A.2. Average visit frequency for each category of each predictor variable in each sample; Appendix Table A.3. Models testing the options for insurance coverage and its effect on out-of-pocket visit costs; Appendix Table A.4. Full results of the final hierarchical linear models predicting chiropractic visit frequency for samples of patients with chronic low back pain and chronic neck pain.

\section{Abbreviations \\ BIC: Bayesian Information Criterion; CLBP: Chronic low back pain; CNP: Chronic neck pain; HLM: Hierarchical linear modeling; NDI: Neck Disability Index; NRS: Numerical rating scale; ODI: Oswestry Disability Index \\ Acknowledgements \\ The authors are grateful for the funding received from $\mathrm{NCCIH}$ and NCMIC Foundation for this project.}

\section{Authors' contributions}

$\mathrm{PMH}$ and IDC conceived of the idea for this study. PMH and SEE analyzed the data and IDC and ELH suggested additional analyses and helped interpret the results. PMH wrote the first draft of the manuscript and all authors provided comments and edits to subsequent drafts and read and approved the final manuscript. 


\section{Funding}

The data used in this study were collected under a cooperative agreement (U19) from the National Center for Complementary and Integrative Health (NCCIH). Grant No. 1U19AT007912-01. The analyses in this study were funded by a grant from the National Chiropractic Mutual Insurance Company (NCMIC) Foundation. Neither funding body had a role in the design of the study; the collection, analysis, and interpretation of data; and in writing the manuscript.

\section{Availability of data and materials}

The datasets generated and/or analysed during the current study are not publicly available due to this provision not being included in participants' consent forms but are available from the corresponding author on reasonable request.

\section{Ethics approval and consent to participate}

The project was approved by the Human Subjects Protection Committee at the RAND Corporation and all participants gave written consent.

\section{Consent for publication}

Not applicable.

\section{Competing interests}

The authors declare that they have no competing interests.

\section{Author details}

${ }^{1}$ RAND Corporation, Santa Monica, CA, USA. ${ }^{2}$ Office of Public Health Studies, University of Hawaii, Honolulu, HI, USA.

\section{Received: 4 March 2020 Accepted: 5 May 2020}

Published online: 13 May 2020

\section{References}

1. Johannes CB, Le TK, Zhou X, Johnston JA, Dworkin RH. The prevalence of chronic pain in United States adults: results of an internet-based survey. J Pain. 2010;11(11):1230-9.

2. Institute of Medicine. Relieving Pain in America: a blueprint for transforming prevention, care, education, and research. Washington, DC: The National Academies Press; 2011

3. Meucci RD, Fassa AG, Faria NMX. Prevalence of chronic low back pain: systematic review. Rev Saude Publica. 2015;49:1-9.

4. Freburger JK, Holmes GM, Agans RP, Jackman AM, Darter JD, Wallace AS, et al. The rising prevalence of chronic low back pain. Arch Intern Med. 2009; 169(3):251-8.

5. Webb R, Brammah T, Lunt M, Urwin M, Allison T, Symmons D. Prevalence and predictors of intense, chronic, and disabling neck and back pain in the UK general population. Spine. 2003;28(11):1195-202.

6. Bovim G, Schrader H, Sand T. Neck pain in the general population. Spine. 1994;19(12):1307-9.

7. Guez M, Hildingsson C, Nilsson M, Toolanen G. The prevalence of neck pain. Acta Orthop Scand. 2002;73(4):455-9.

8. Cassidy JD, Cote P, Carroll LJ, Kristman V. Incidence and course of low back pain episodes in the general population. Spine. 2005:30(24):2817-23.

9. Hestbaek L, Leboeuf-Yde C, Manniche C. Low back pain: what is the longterm course? A review of studies of general patient populations. Eur Spine J. 2003;12(2):149-65

10. Hogg-Johnson S, Van Der Velde G, Carroll LJ, Holm LW, Cassidy JD, Guzman $J$, et al. The burden and determinants of neck pain in the general population. Eur Spine J. 2008;17(1):39-51.

11. Tsang A, Von Korff M, Lee S, Alonso J, Karam E, Angermeyer MC, et al. Common chronic pain conditions in developed and developing countries: gender and age differences and comorbidity with depression-anxiety disorders. J Pain. 2008;9(10):883-91.

12. Gore M, Sadosky A, Stacey BR, Tai K-S, Leslie D. The burden of chronic low back pain: clinical comorbidities, treatment patterns, and health care costs in usual care settings. Spine. 2012:37(11):E668-E77.

13. Martin BI, Deyo RA, Mirza SK, Turner JA, Comstock BA, Hollingworth W, et al. Expenditures and health status among adults with back and neck problems. JAMA. 2008;299(6):656-64.
14. Stewart WF, Ricci JA, Chee E, Morganstein D, Lipton R. Lost productive time and cost due to common pain conditions in the US workforce. JAMA. 2003; 290(18):2443-54.

15. Herman PM, Kommareddi M, Sorbero ME, Rutter CM, Hays RD, Hilton LG, et al. Characteristics of chiropractic patients being treated for chronic low back and chronic neck pain. J Manip Physiol Ther. 2018;41(6):445-55.

16. Knauer SR, Freburger JK, Carey TS. Chronic low back pain among older adults: a population-based perspective. J Aging Health. 2010;22(8):1213-34.

17. Verkerk K, Luijsterburg P, Heymans M, Ronchetti I, Pool-Goudzwaard A, Miedema $\mathrm{H}$, et al. Prognosis and course of pain in patients with chronic non-specific low back pain: a 1-year follow-up cohort study. Eur J Pain. 2015;19(8):1101-10.

18. Evans R, Bronfort G, Nelson B, Goldsmith CH. Two-year follow-up of a randomized clinical trial of spinal manipulation and two types of exercise for patients with chronic neck pain. Spine. 2002:27(21):2383-9.

19. Niemistö L, Lahtinen-Suopanki T, Rissanen P, Lindgren K-A, Sarna S, Hurri H. A randomized trial of combined manipulation, stabilizing exercises, and physician consultation compared to physician consultation alone for chronic low back pain. Spine. 2003:28(19):2185-91.

20. Ivanova Jl, Birnbaum HG, Schiller M, Kantor E, Johnstone BM, Swindle RW. Real-world practice patterns, health-care utilization, and costs in patients with low back pain: the long road to guideline-concordant care. Spine J. 2011;11(7):622-32.

21. National Pain Strategy Task Force. National Pain Strategy: A Comprehensive Population Health-Level Strategy for Pain. Bethesda, MD: Interagency Pain Research Coordinating Committee (IPRCC), National Institutes of Health $(\mathrm{NIH}) ; 2015$.

22. Qaseem A, Wilt TJ, McLean RM, Forciea MA. Noninvasive treatments for acute, subacute, and chronic low back pain: a clinical practice guideline from the American College of Physicians. Ann Intern Med. 2017;166(7):514-30.

23. The Diagnosis and Treatment of Low Back Pain Work Group. VA/DoD Clinical Practice Guideline for Diagnosis and Treatment of Low Back Pain, Version 2.0. Washington, DC: The Office of Quality, Safety and Value, VA, \& Office of Evidence Based Practice, U.S. Army Medical Command; 2017.

24. U.S. Department of Health and Human Services. Pain Management Best Practices Inter-Agency Task Force Report: Updates, Gaps, Inconsistencies, and Recommendations. Washington, DC: U. S. Department of Health and Human Services; 2019 May.

25. Goertz CM, George SZ. Insurer Coverage of Nonpharmacological Treatments for Low Back Pain-Time for a Change. JAMA Network Open. 2018;1(6): e183037-e.

26. Heyward J, Jones CM, Compton WM, Lin DH, Losby JL, Murimi IB, et al. Coverage of nonpharmacologic treatments for low back pain among US public and private insurers. JAMA Network Open. 2018;1(6):e183044-e.

27. Schatman ME. The role of the health insurance industry in perpetuating suboptimal pain management. Pain Med. 2011;12(3):415-26.

28. Gonen JS. Neither prevention nor cure: managed care for women with chronic conditions. Womens Health Issues. 1999;9(2):68S-78S

29. Bishai D, Paina L, Li Q, Peters DH, Hyder AA. Advancing the application of systems thinking in health: why cure crowds out prevention. Health research policy and systems. 2014;12(1):28

30. Globe GA, Morris CE, Whalen WM, Farabaugh RJ, Hawk C. Chiropractic management of low back disorders: report from a consensus process. Manip Physiol Ther. 2008;31(9):651-8.

31. Globe G, Farabaugh RJ, Hawk C, Morris CE, Baker G, Whalen WM, et al. Clinical practice guideline: chiropractic care for low back pain. J Manip Physiol Ther. 2016;39(1):1-22.

32. Farabaugh RJ, Dehen MD, Hawk C. Management of chronic spine-related conditions: consensus recommendations of a multidisciplinary panel. $J$ Manip Physiol Ther. 2010;33(7):484-92.

33. Colorado Division of Workers' Compensation. Low back pain medical treatment guidelines. Denver, CO: Colorado Division of Workers' Compensation; 2014 Feb 3.

34. Colorado Division of Workers' Compensation. Cervical spine injury medical treatment guidelines. Denver, CO: Colorado Division of Workers' Compensation; 2014 Feb 3.

35. Canadian Chiropractic Association and Canadian Federation of Chiropractic Regulatory Boards Clinical Practice Guidelines Development Initiative Guidelines Development Committee. Chiropractic clinical practice guideline: evidence-based treatment of adult neck pain not due to whiplash. The Journal of the Canadian Chiropractic Association 2005;49(3):158-209. 
36. California Division of Workers' Compensation. Medical Treatment Utilization Schedule (MTUS) Chronic Pain Medical Treatment Guidelines Sacramento, CA: State of California; 2016.

37. Penney LS, Ritenbaugh C, DeBar LL, Elder C, Deyo RA. Provider and patient perspectives on opioids and alternative treatments for managing chronic pain: a qualitative study. BMC Fam Pract. 2016;17(1):164.

38. Martin Bl, Gerkovich MM, Deyo RA, Sherman KJ, Cherkin DC, Lind BK, et al. The association of complementary and alternative medicine use and health care expenditures for back and neck problems. Med Care. 2012;50(12):1029-36.

39. Coulter ID, Shekelle PG. Chiropractic in North America: a descriptive analysis. J Manip Physiol Ther. 2005;28(2):83-9.

40. Hurwitz EL, Coulter ID, Adams AH, Genovese BJ, Shekelle PG. Use of chiropractic services from 1985 through 1991 in the United States and Canada. Am J Public Health. 1998;88(5):771-6.

41. Mootz RD, Cherkin DC, Odegard CE, Eisenberg DM, Barassi JP, Deyo RA. Characteristics of chiropractic practitioners, patients, and encounters in Massachusetts and Arizona. J Manip Physiol Ther. 2005;28(9):645-53.

42. Stevans JM, Zodet MW. Clinical, demographic, and geographic determinants of variation in chiropractic episodes of care for adults using the 2005-2008 medical expenditure panel survey. J Manip Physiol Ther. 2012;35(8):589-99.

43. Herman PM, Edgington SE, Ryan GW, Coulter ID. Prevalence and Characteristics of Chronic Spinal Pain Patients with Different Hopes (Treatment Goals) for Ongoing Chiropractic Care. J Altern Complement Med. 2019;[Published online ahead of print](DOl:https://doi.org/10.1089/ acm.2019.0247)

44. Herman PM, Luoto JE, Kommareddi M, Sorbero ME, Coulter ID. Patient willingness to pay (WTP) for reductions in chronic low back pain and chronic neck pain. J Pain. 2019; [in press].

45. Fairbank JCT, Couper J, Davies JB, O'Brien JP. The Oswestry low back pain disability questionnaire. Physiotherapy. 1980;66(8):271-3.

46. Vernon H. The neck disability index: state-of-the-art, 1991-2008. J Manip Physiol Ther. 2008;31(7):491-502.

47. Hays RD, Spritzer KL, Sherbourne CD, Ryan GW, Coulter ID. Group and individual-level change on health-related quality of life in chiropractic patients with chronic low Back or neck Pain. Spine. 2019:44(9):647-51.

48. Coulter ID, Herman PM, Ryan GW, Hays RD, Hilton LG, Whitley MD. Researching the appropriateness of care in the complementary and integrative health (CIH) professions: part 1. J Manip Physiol Ther. 2019;41(9): 800-6.

49. Coulter ID, Herman PM, Ryan GW, Hays RD, Hilton LJ, Team CERC. The challenge of determining appropriate Care in the era of patient-centered care and rising health care costs. J Health Serv Res Policy. 2019;24(3):201-6.

50. Iyiewuare PO, Coulter ID, Whitley MD, Herman PM. Researching the Appropriateness of Care in the Complementary and Integrative Health Professions: Part 2: What Every Researcher and Practitioner Should Know About the Health Insurance Portability and Accountability Act and PracticeBased Research in the United States J Manipulative Physiol Ther. 2019;41(9): 807-13.

51. Whitley MD, Coulter ID, Ryan G, Hays RD, Sherbourne C, Herman PM, et al. Researching the Appropriateness of Care in the Complementary and Integrative Health $(\mathrm{ClH})$ Professions Part 3. Designing Instruments with Patient Input. J Manipulative Physiol Ther. 2019 https://www.jmptonline.org/ article/S0161-4754(18)30364-6/pdf.

52. Coulter ID, Whitley MD, Ryan GW, Aliyev G, lyiewuare P, Kraus L, et al. Researching the Appropriateness of Care in the Complementary and Integrative Health Professions Part 4: Putting the P into EBP in Chiropractic: Recruiting Clinics and Patients. . J Manipulative Physiol Ther. 2019; [in press].

53. Christensen MG, Hyland JK, Goertz CM, Kollasch MW. Practice analysis of chiropractic 2015. Greeley, CO: National Board of Chiropractic Examiners; 2015.

54. Andersen RM, McCutcheon A, Aday LA, Chiu GY, Bell R. Exploring dimensions of access to medical care. Health Serv Res. 1983;18(1):49-74.

55. Babitsch B, Gohl D, von Lengerke T. Re-revisiting Andersen's behavioral model of health services use: a systematic review of studies from 19982011. GMS Psycho-Social-Medicine. 2012;9

56. Bradley EH, McGraw SA, Curry L, Buckser A, King KL, Kasl SV, et al. Expanding the Andersen model: the role of psychosocial factors in long-term care use. Health Serv Res. 2002;37(5):1221-42.

57. Huskisson E. Measurement of pain. Lancet. 1974;304(7889):1127-31.

58. Vernon $H$, Mior S. The neck disability index: a study of reliability and validity. J Manip Physiol Ther. 1991;14(7):409.
59. Bijur PE, Latimer CT, Gallagher EJ. Validation of a verbally administered numerical rating scale of acute pain for use in the emergency department. Acad Emerg Med. 2003;10(4):390-2.

60. Childs JD, Piva SR, Fritz JM. Responsiveness of the numeric pain rating scale in patients with low back pain. Spine. 2005;30(11):1331.

61. Downie W, Leatham P, Rhind V, Wright V, Branco J, Anderson J. Studies with pain rating scales. Ann Rheum Dis. 1978;37(4):378-81.

62. Paice JA, Cohen FL. Validity of a verbally administered numeric rating scale to measure cancer pain intensity. Cancer Nurs. 1997;20(2):88-93.

63. Salaffi F, Stancati A, Silvestri CA, Ciapetti A, Grassi W. Minimal clinically important changes in chronic musculoskeletal pain intensity measured on a numerical rating scale. Eur J Pain. 2004;8(4):283-91.

64. Cleland JA, Fritz JM, Whitman JM, Palmer JA. The reliability and construct validity of the neck disability index and patient specific functional scale in patients with cervical radiculopathy. Spine. 2006;31(5):598-602.

65. McCarthy MJH, Grevitt M, Silcocks P, Hobbs G. The reliability of the Vernon and Mior neck disability index, and its validity compared with the short form-36 health survey questionnaire. Eur Spine J. 2007;16(12):2111-7.

66. Wheeler AH, Goolkasian P, Baird AC, Darden BV. Development of the neck Pain and disability scale: item analysis, face, and criterion-related validity. Spine. 1999:24(13):1290.

67. Grönblad M, Hupli M, Wennerstrand $P$, Järvinen $E$, Lukinmaa A, Kouri J-P, et al. Inter-correlation and test-retest reliability of the pain disability index (PDI) and the Oswestry disability questionnaire (ODQ) and their correlation with pain intensity in low back pain patients. Clin J Pain. 1993;9(3):189-95.

68. Fisher K, Johnston M. Validation of the Oswestry low back pain disability questionnaire, its sensitivity as a measure of change following treatment and its relationship with other aspects of the chronic pain experience. Physiotherapy theory and practice. 1997;13(1):67-80.

69. Davidson M, Keating JL. A comparison of five low back disability questionnaires: reliability and responsiveness. Phys Ther. 2002;82(1):8-24.

70. Schellingerhout JM, Verhagen AP, Heymans MW, Pool JJM, Vonk F, Koes BW et al. Which subgroups of patients with non-specific neck pain are more likely to benefit from spinal manipulation therapy, physiotherapy, or usual care? Pain. 2008;139(3):670-80.

71. Moffett JAK, Carr J, Howarth E. High fear-avoiders of physical activity benefit from an exercise program for patients with back pain. Spine. 2004;29(11): $1167-72$.

72. Jensen OK, Nielsen CV, Stengaard-Pedersen K. One-year prognosis in sicklisted low back pain patients with and without radiculopathy. Prognostic factors influencing pain and disability. Spine J. 2010;10(8):659-75.

73. Anderson KO, Dowds BN, Pelletz RE, Edwards WT, Peeters-Asdourian C. Development and initial validation of a scale to measure self-efficacy beliefs in patients with chronic pain. Pain. 1995;63(1):77-83.

74. Devilly GJ, Borkovec TD. Psychometric properties of the credibility/ expectancy questionnaire. J Behav Ther Exp Psychiatry. 2000;31(2):73-86.

75. Smeets R, Beelen S, Goossens M, Schouten E, Knottnerus J, Vlaeyen JWS Chapter 7: treatment expectancy and credibility are associated with the outcome of both physical and cognitive-behavioral treatment in chronic low back pain. In: Smeets $R$, editor. Active rehabilitation for chronic low back pain: cognitive-behavioral, physical, or both? Eindhoven. The Netherlands: Maastricht University; 2008. p. 138-60.

76. Smeets RJ, Maher CG, Nicholas MK, Refshauge KM, Herbert RD. Do psychological characteristics predict response to exercise and advice for subacute low back pain? Arthritis Care Res (Hoboken). 2009;61(9):1202-9.

77. HealthMeasures. PROMIS Adult Profile Scoring Manual. Evanston, IL: Northwestern University; 2019.

78. Amtmann D, Kim J, Chung H, Bamer AM, Askew RL, Wu S, et al. Comparing CESD-10, PHQ-9, and PROMIS depression instruments in individuals with multiple sclerosis. Rehabil Psychol. 2014;59(2):220.

79. Hill JC, Lewis M, Sim J, Hay EM, Dziedzic K. Predictors of poor outcome in patients with neck pain treated by physical therapy. Clin J Pain. 2007:23(8):683-90.

80. Smeets RJ, Vlaeyen JW, Kester AD, Knottnerus JA. Reduction of pain catastrophizing mediates the outcome of both physical and cognitivebehavioral treatment in chronic low back pain. J Pain. 2006;7(4):261-71.

81. van der Windt DA, Kuijpers T, Jellema P, van der Heijden GJ, Bouter LM. Do psychological factors predict outcome in both low-back pain and shoulder pain? Ann Rheum Dis. 2007:66(3):313-9.

82. Cook CE, Learman KE, O'halloran BJ, Showalter CR, Kabbaz VJ, Goode AP, et al. Which prognostic factors for low back pain are generic predictors of outcome across a range of recovery domains? Phys Ther. 2013;93(1):32-40. 
83. Underwood M, Morton V, Farrin A, Team UBT. Do baseline characteristics predict response to treatment for low back pain? Secondary analysis of the UK BEAM dataset [ISRCTN32683578]. Rheumatology. 2007;46(8):1297-302.

84. Niemisto L, Sarna S, Lahtinen-Suopanki T, Lindgren K-A, Hurri H. Predictive factors for 1-year outcome of chronic low back pain following manipulation, stabilizing exercises, and physician consultation or physician consultation alone. J Rehabil Med. 2004;36(3):104-9.

85. Dionne C, Von Korff M, Koepsell T, Deyo R, Barlow W, Checkoway H. Formal education and back pain: a review. J Epidemiol Community Health. 2001; 55(7):455-68.

86. US Census Bureau. 2010 Census Urban and Rural Classification and Urban Area Criteria Suitland-Silver Hill, MD: US Department of Commerce; 2018 [Available from: https:/www.census.gov/programs-surveys/geography/ guidance/geo-areas/urban-rural/2010-urban-rural.html.

87. Federal Office of Rural Health Policy. Defining Rural Population Rockville, MD: Health Resources \& Services Administration; 2018 [updated December 2018. Available from: https://www.hrsa.gov/rural-health/about-us/definition/ index.html.

88. Heo M, Faith MS, Mott JW, Gorman BS, Redden DT, Allison DB. Hierarchical linear models for the development of growth curves: an example with body mass index in overweight/obese adults. Stat Med. 2003;22:1911-42.

89. Raudenbush SW, Bryk AS. Hierarchical linear models: applications and data analysis methods. Second edition ed. Thousand Oaks, CA: Sage Publications; 2002. 483 p.

90. Singer JD, Using SAS. PROC MIXED to fit multilevel models, hierarchical models, and individual growth curve models. J Educ Behav Stat. 1998;24(4): 323-55

91. Feldman HA. Families of lines: random effects in linear regression analysis. J Appl Physiol. 1988;64(4):1721-32.

92. Whittaker TA, Furlow CF. The comparison of model selection criteria when selecting among competing hierarchical linear models. J Mod Appl Stat Methods. 2009:8(1):15.

93. Raftery AE. Bayesian model selection in social research. Soc Method. 1995; 25:111-64.

94. Lipsey MW. Theory as method: small theories of treatments. New Directions for Program Evaluation. 1993;1993(57):5-38.

95. Gliedt JA, Schneider MJ, Evans MW, King J, Eubanks JE. The biopsychosocial model and chiropractic: a commentary with recommendations for the chiropractic profession. Chiropr Man Therap. 2017;25(1):16.

96. Homola S. Real orthopaedic subluxations versus imaginary chiropractic subluxations. Focus Altern Complement Ther. 2010;15(4):284-7.

97. Simpson JK. The five eras of chiropractic \& the future of chiropractic as seen through the eyes of a participant observer. Chiropr Man Therap. 2012;20(1):1

98. Nyiendo J, Haas M, Goldberg B, Sexton G. Patient characteristics and physicians' practice activities for patients with chronic low back pain: a practice-based study of primary care and chiropractic physicians. J Manip Physiol Ther. 2001;24(2):92-100

99. Chronic Pain. Symptoms, diagnosis, \& treatment. NIH Medline Plus. 2011:5-6.

\section{Publisher's Note}

Springer Nature remains neutral with regard to jurisdictional claims in published maps and institutional affiliations.

Ready to submit your research? Choose BMC and benefit from:

- fast, convenient online submission

- thorough peer review by experienced researchers in your field

- rapid publication on acceptance

- support for research data, including large and complex data types

- gold Open Access which fosters wider collaboration and increased citations

- maximum visibility for your research: over $100 \mathrm{M}$ website views per year

At $\mathrm{BMC}$, research is always in progress.

Learn more biomedcentral.com/submissions 